\title{
Antares DLR-H2 - Flying Test Bed for Development of Aircraft Fuel Cell Systems
}

Fuel Cell Seminar 2013

24.10.2013

Dr. J. Kallo, P. Rathke, S. Flade, T. Stephan, Dr. J. Schirmer

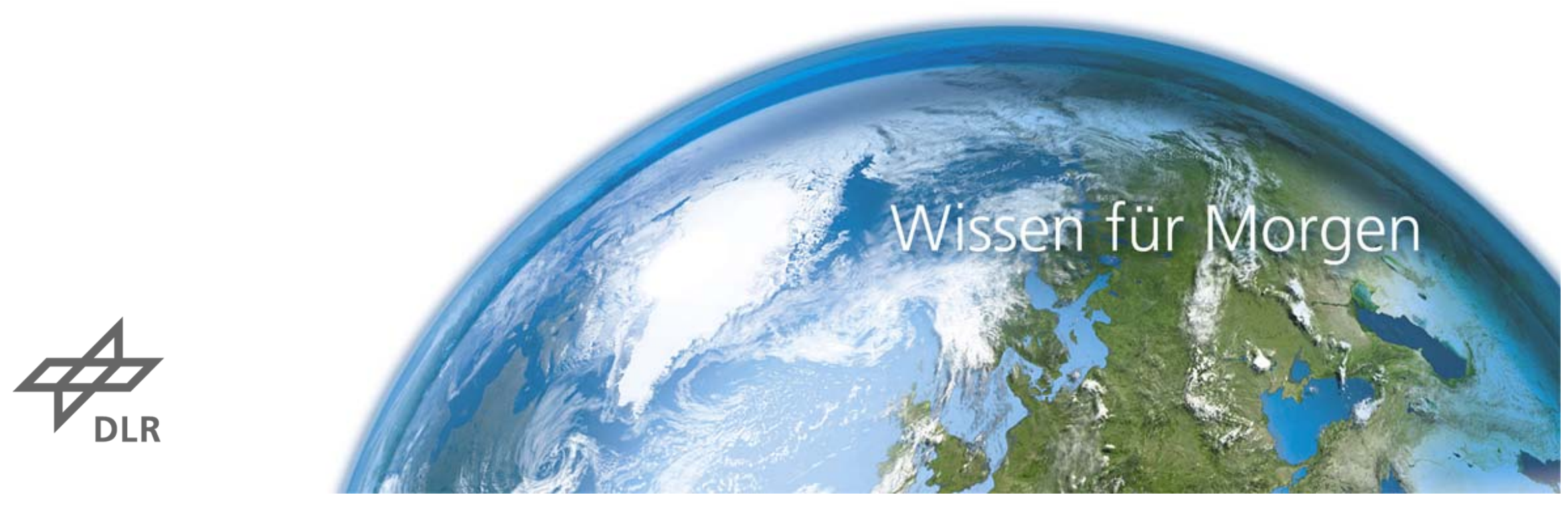




\section{Short Presentation DLR}

DLR is the Aerospace Research Center as well as the Space Agency of the Federal Republic of Germany

Research Areas

- Space Flight

- German Space Agency

- Aeronautics

- Transport Research

- Energy Technology

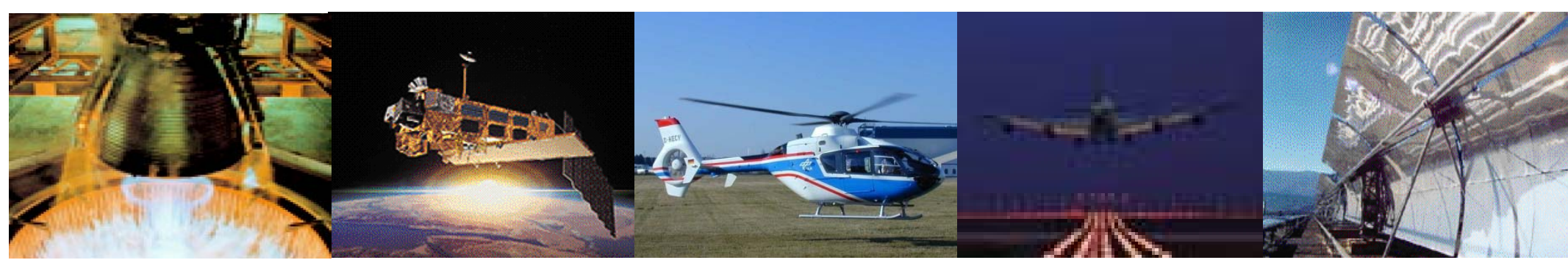

$4_{\text {DLR }}^{4}$

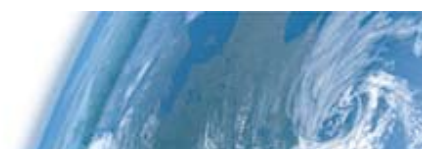




\section{DLR - Sites and employees}

7.000 employees working in 31 research institutes and facilities

at 8 sites

- in 7 field offices.

Offices in Brussels, Paris and Washington.

Fuel cell research in Hamburg and Stuttgart
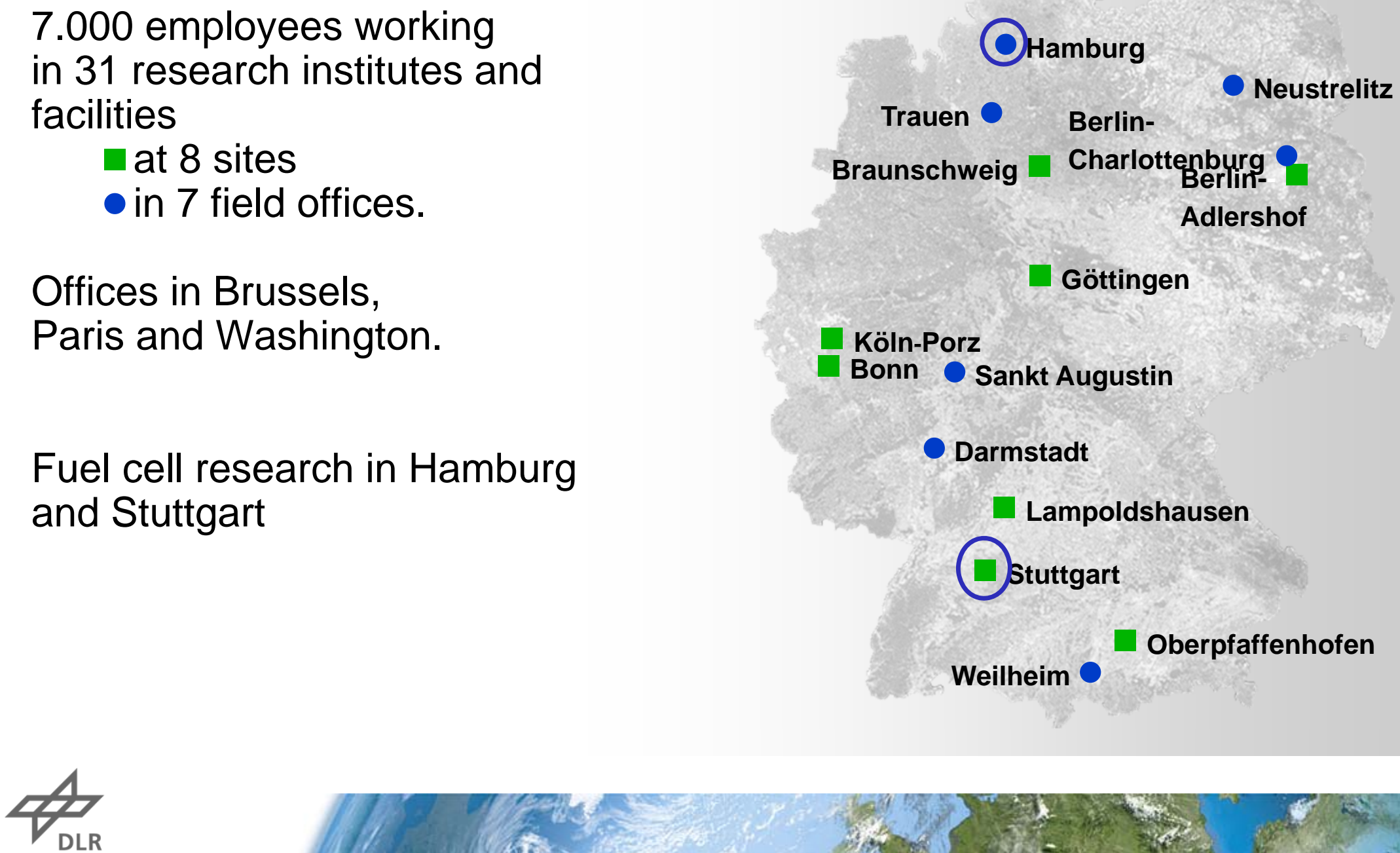


\section{DLR - Institute of Technical Thermodynamics Electrochemical Systems}
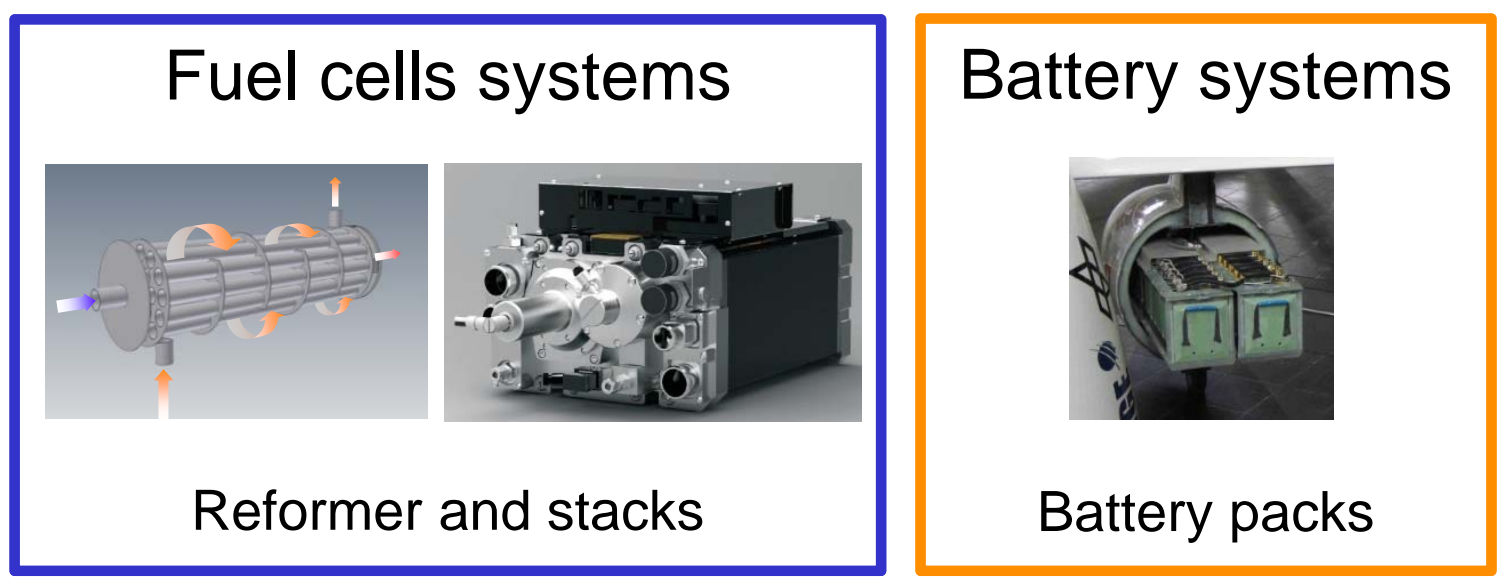

\section{Hybrid systems}
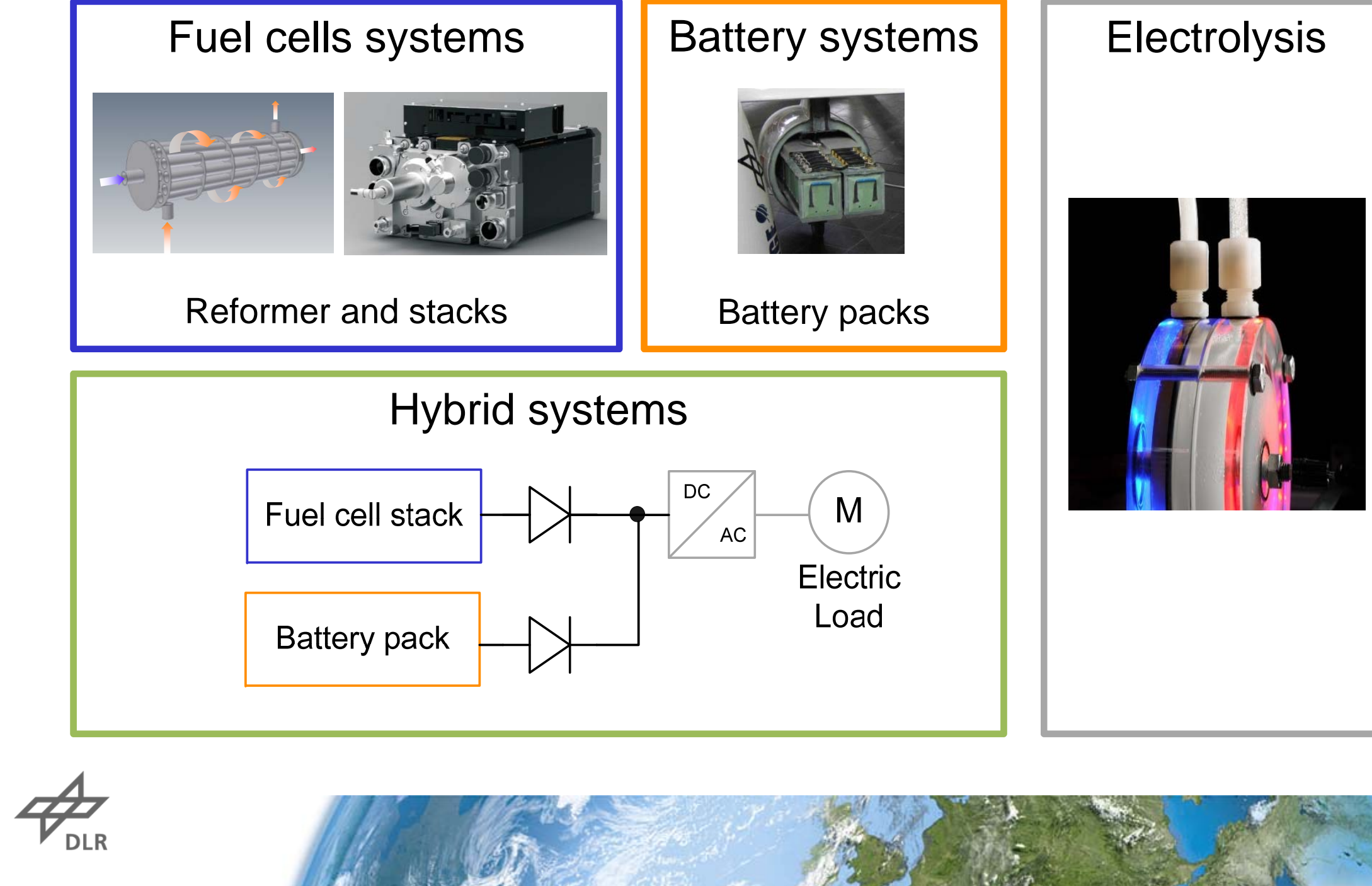


\section{Fuel Cell Aircraft and Airport Applications at the DLR}

Airworthy technology development platform for $\mathrm{A} 320$

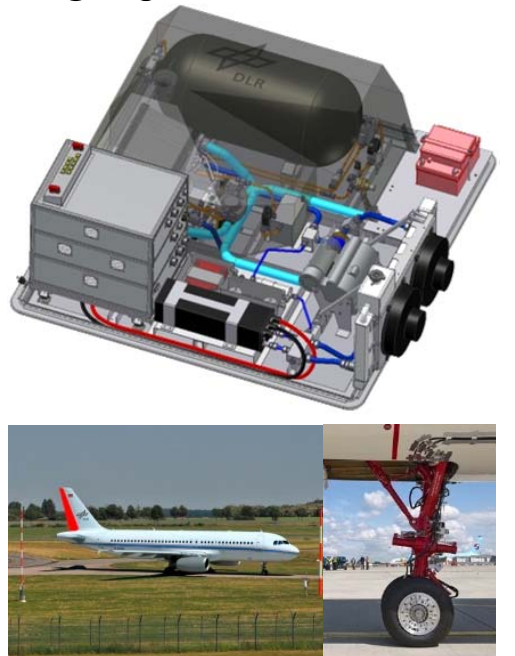

- for emergengy power

- for multifunctional use $\rightarrow$ APU

- energy source for nose wheel drive

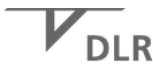

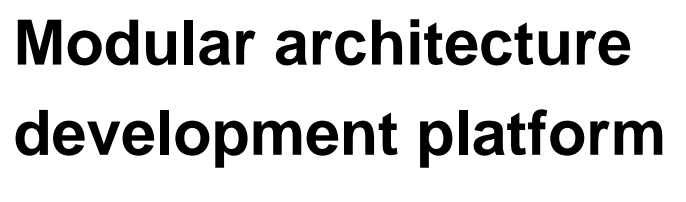

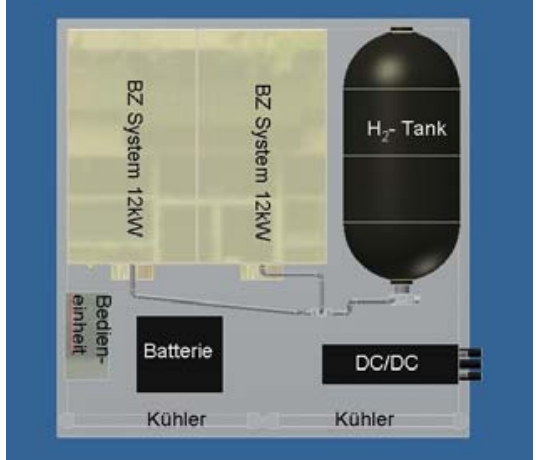

- for GPU applications

- for high torque airport applications (transport) I r - - - - - - - - - ר

Modular airworthy propulsion platform Antares DLR H2

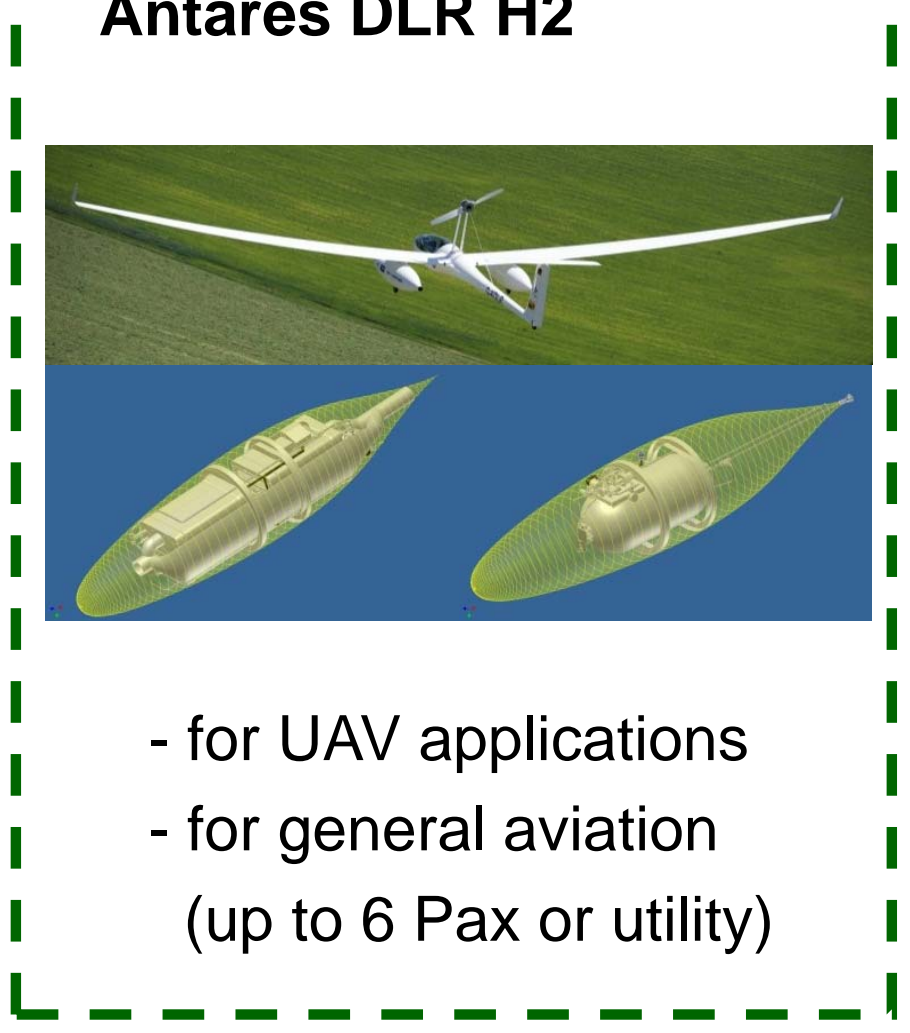




\section{Antares DLR-H2 - overview, build-up}

High efficient airplane
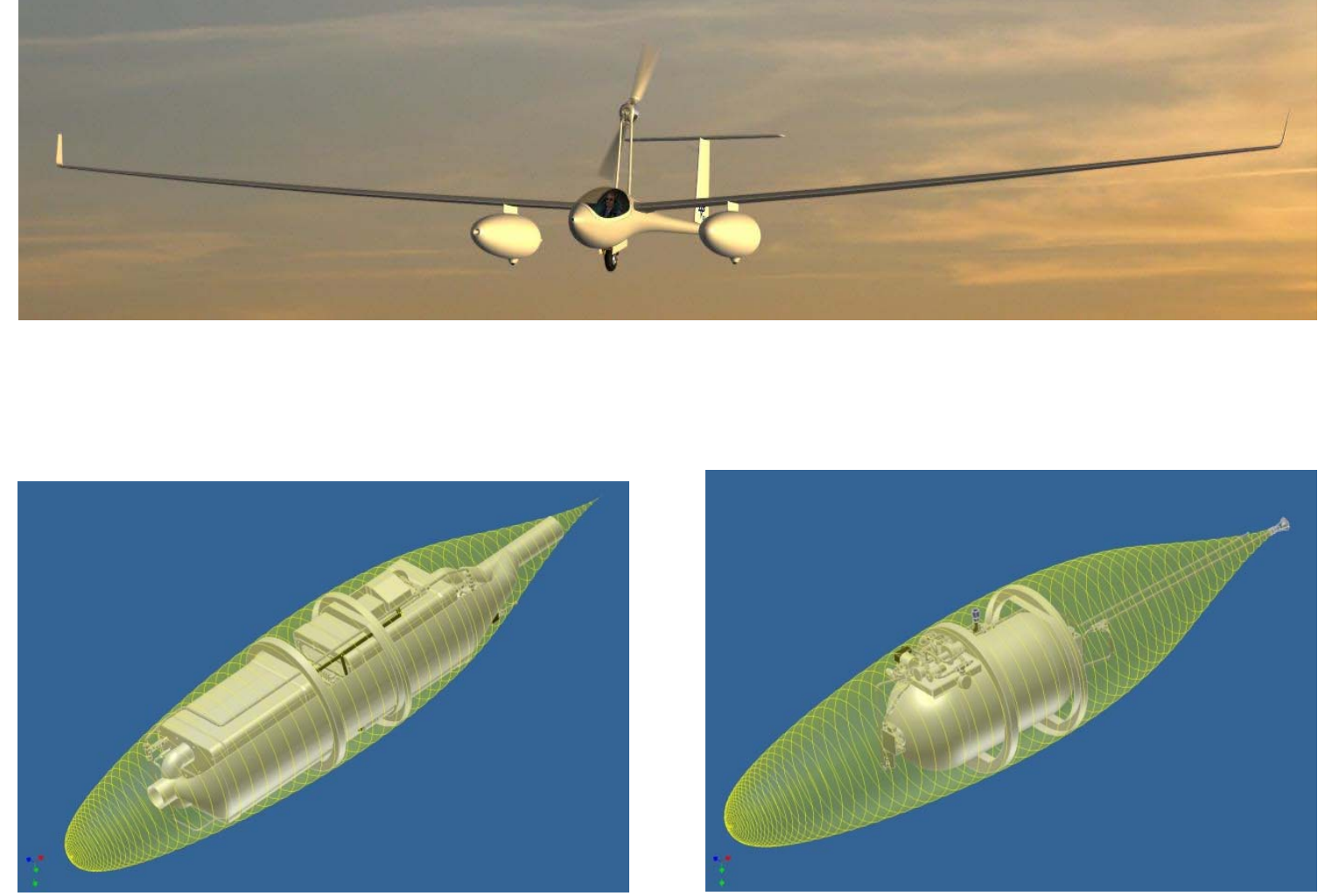

Fuel cell system

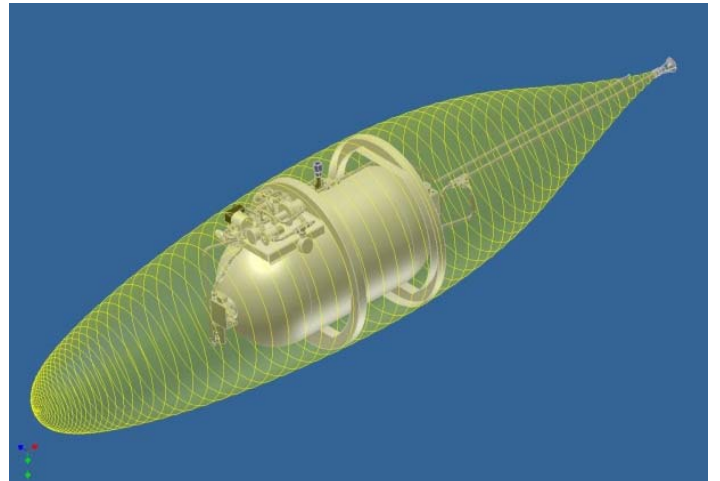

Hydrogen storage
Technical Challenges:

- High efficient fuel cell system

- Minimized air drag

- Optimized aeroelastics

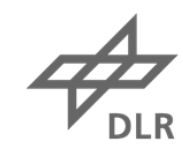




\section{Hydrogen storage system}

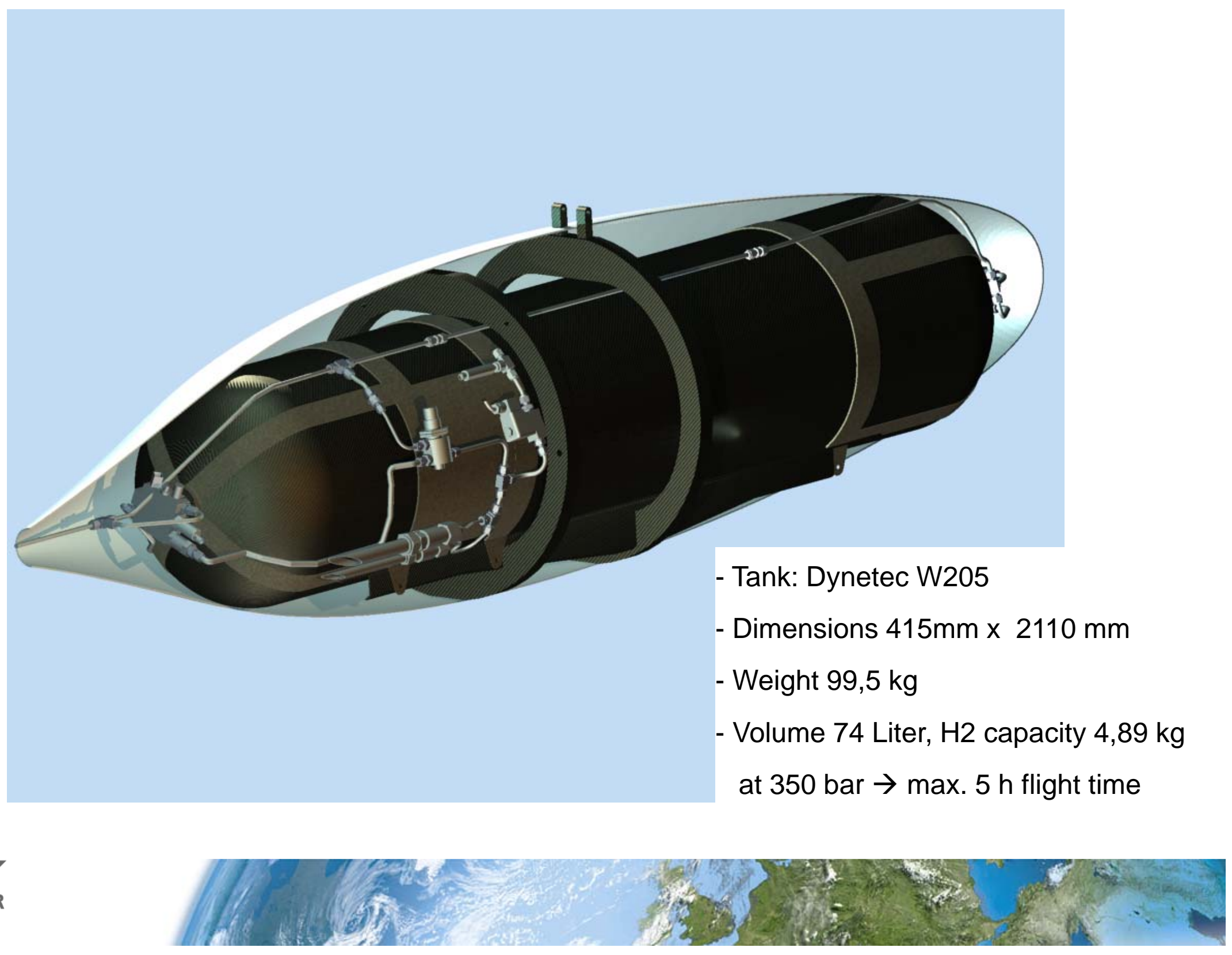




\section{Fuel cell technology Antares DLR H2}

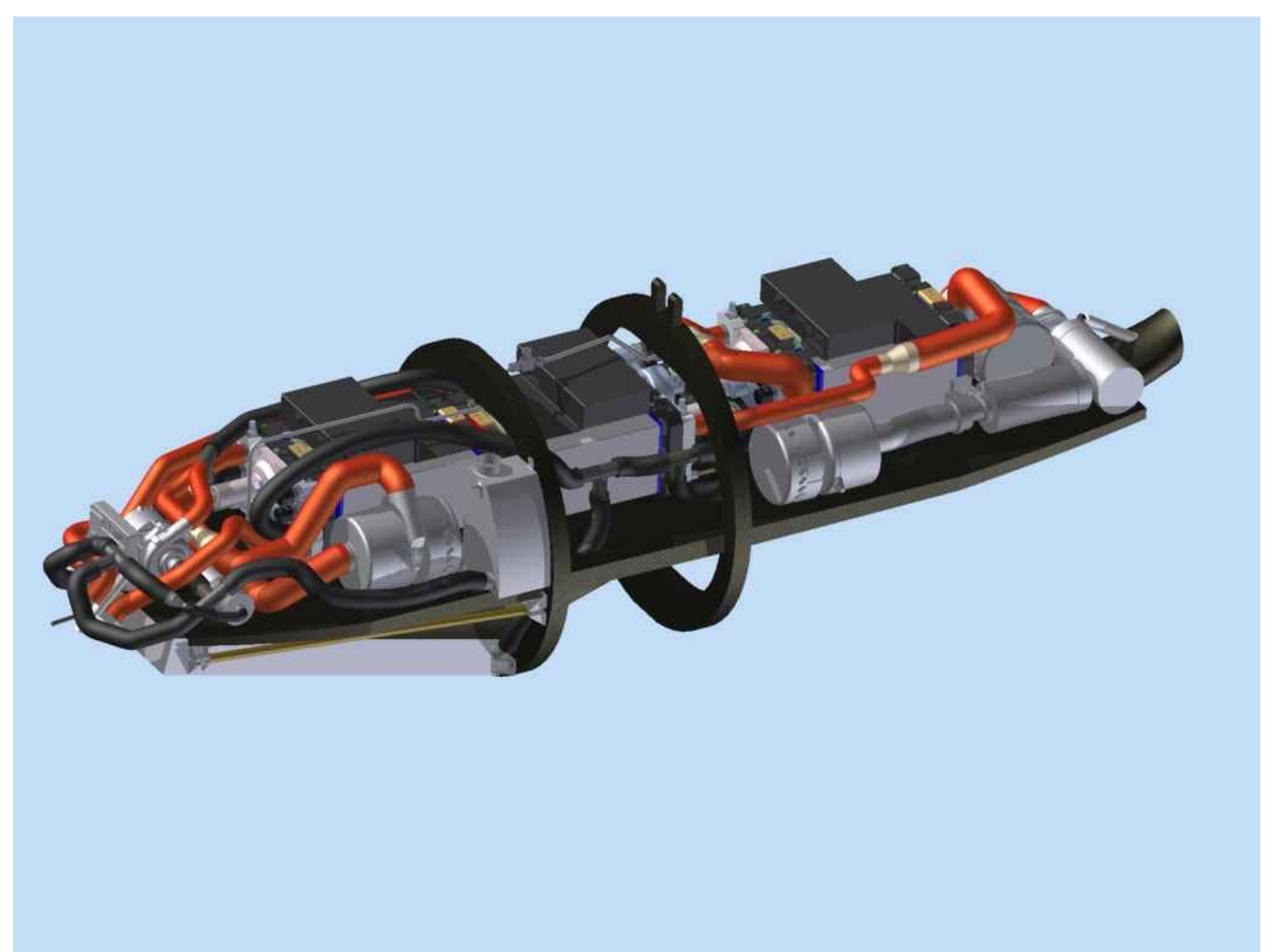

Fuel cell system power up to $33 \mathrm{kWnet}$

$\rightarrow$ modular system $3 \times 11 \mathrm{~kW}$

$\rightarrow$ liquid cooled

Modular fuel cell system with cooling booster
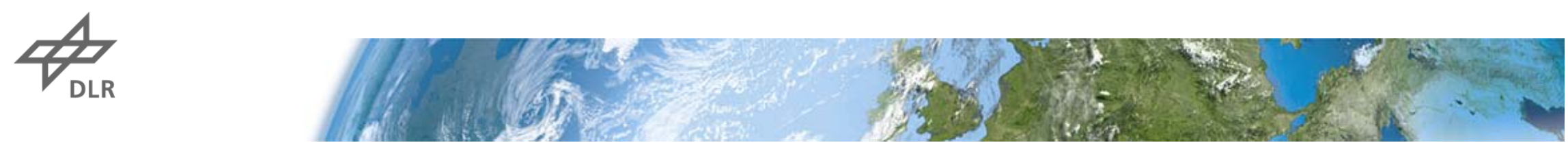


\section{Antares DLR H2 - LT PEM Fuel Cell Technology Gen 2 Optimized electrical network - direct hybrid}

$>40 \%$ overall efficiency (from chemical energy to movement)

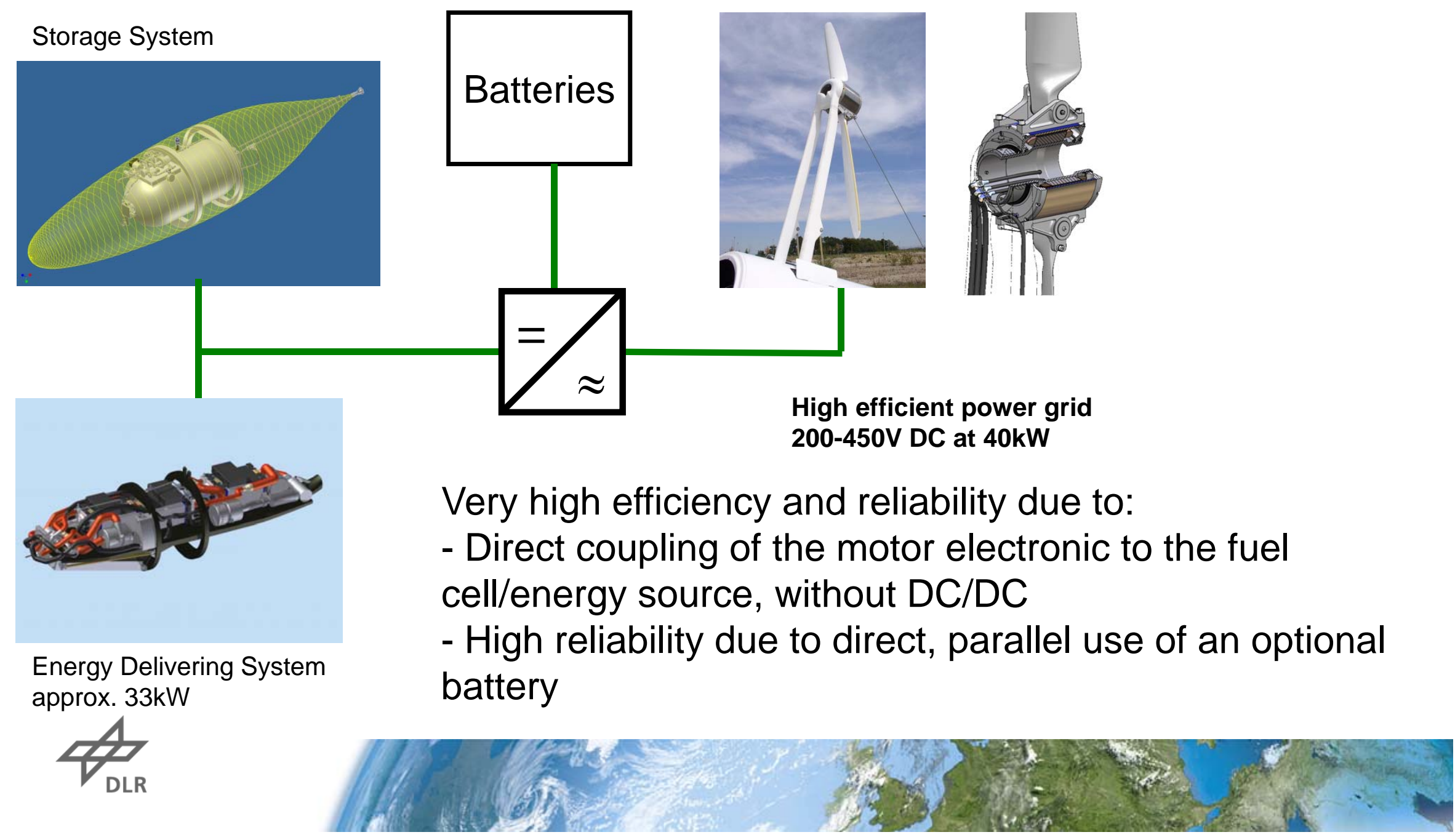




\section{Aircraft application: Flight profile}
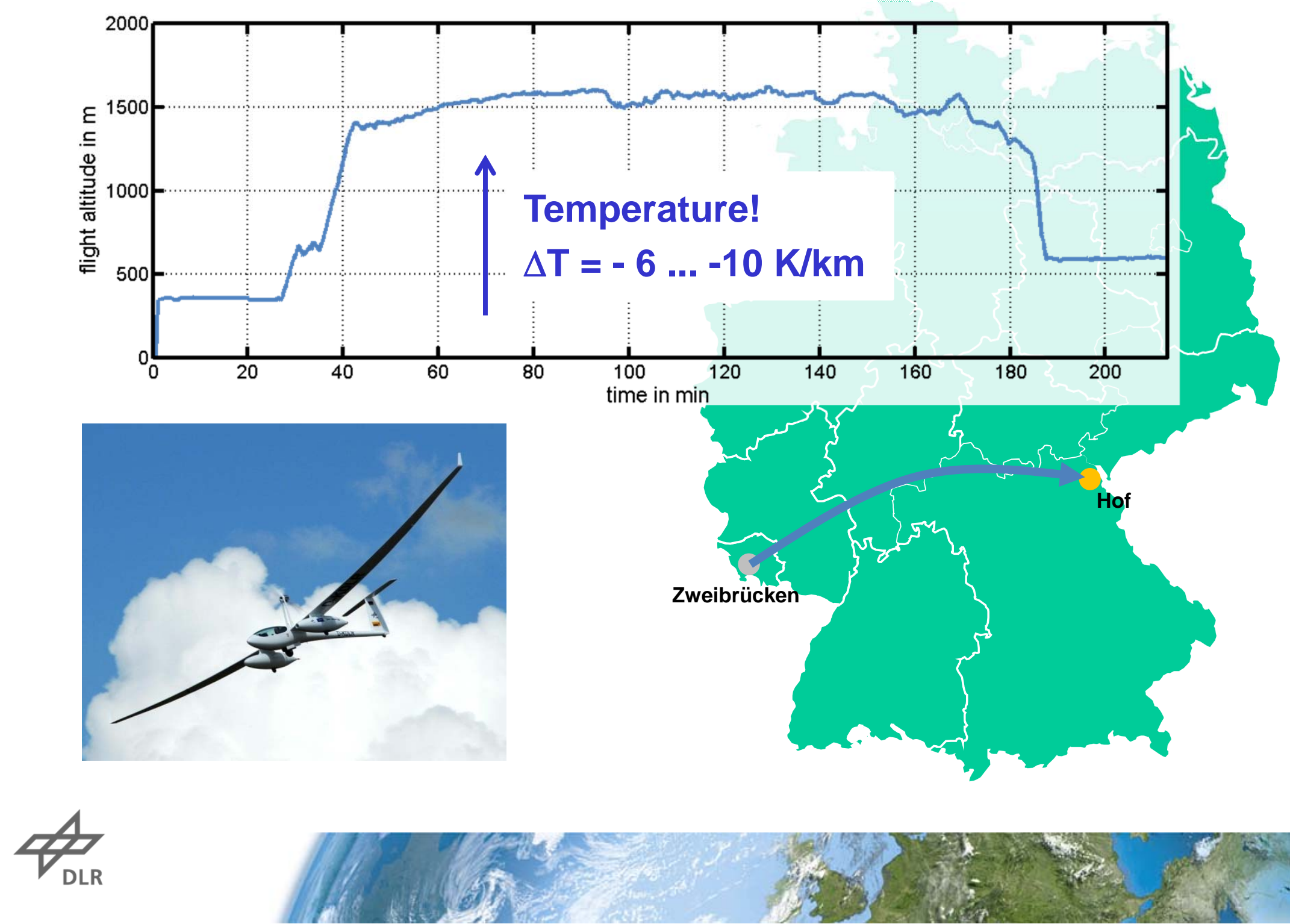


\section{Fuel cell system performance}

"on ground" (150m) vs. "in flight" (1200-1600m)

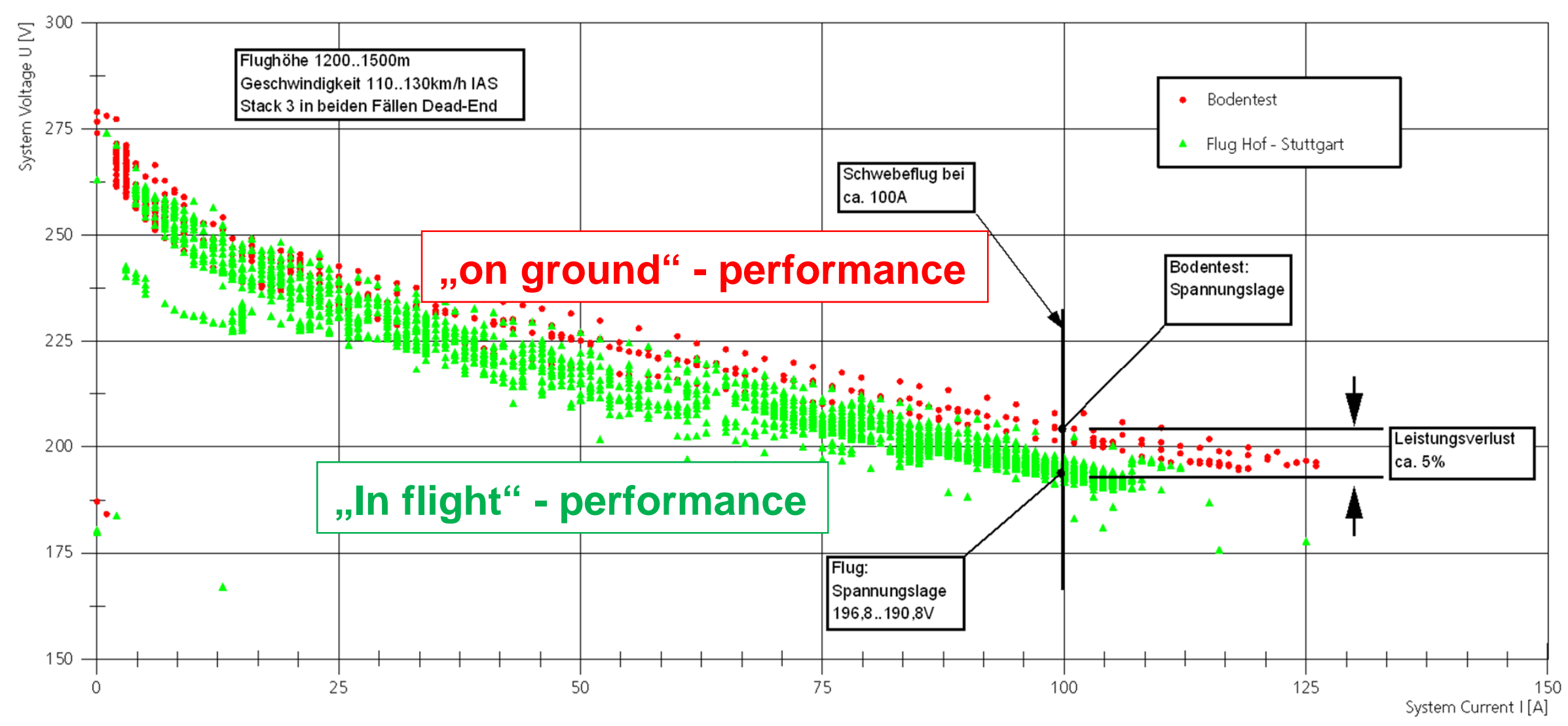

- summarized performance loss „in flight“ due to altitude and cooling effects ca. $5 \%$

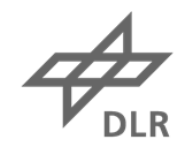




\section{Concept of the direct hybrid}
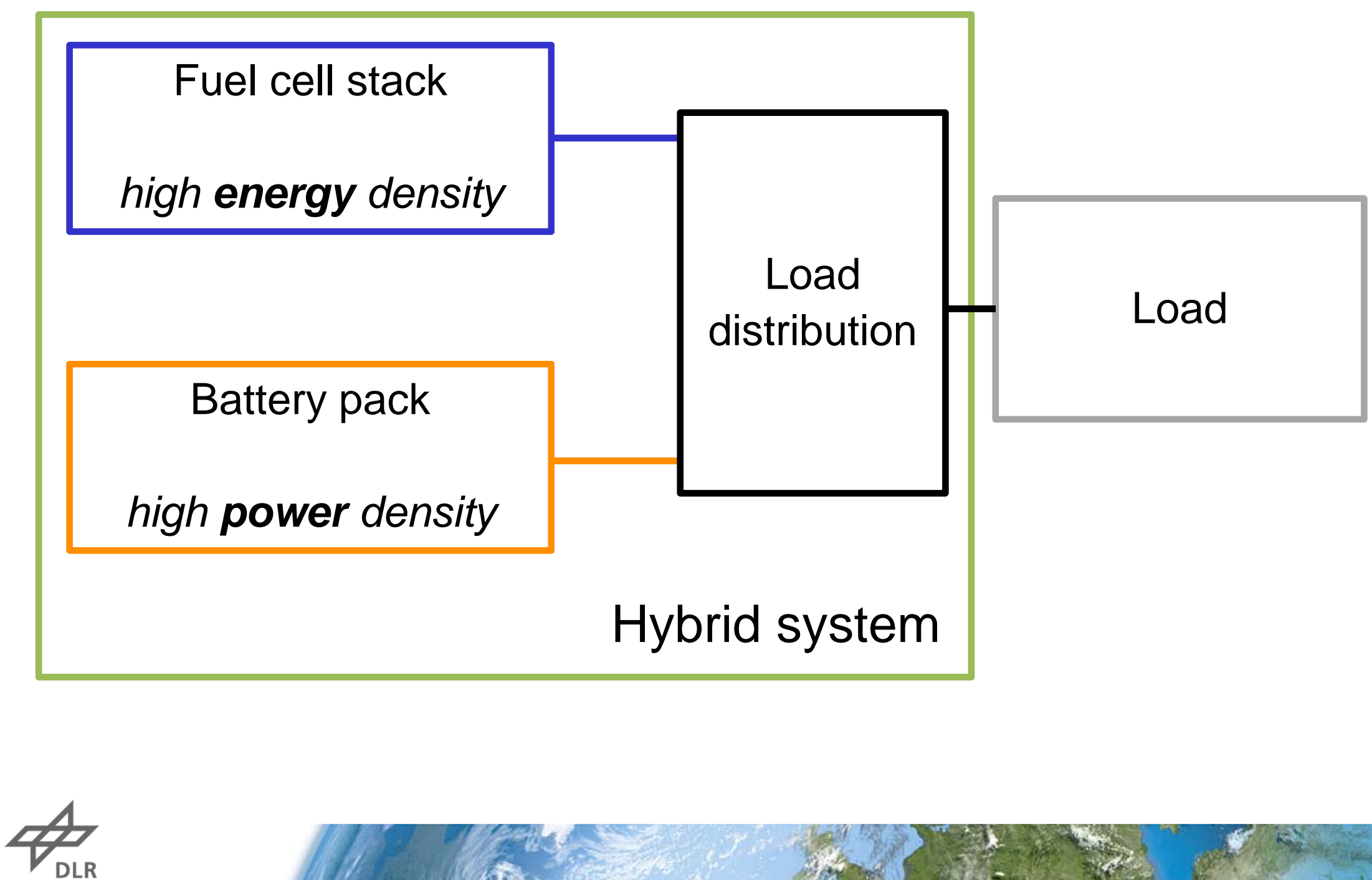


\section{Concept of the direct hybrid}

Conventional hybrid systems

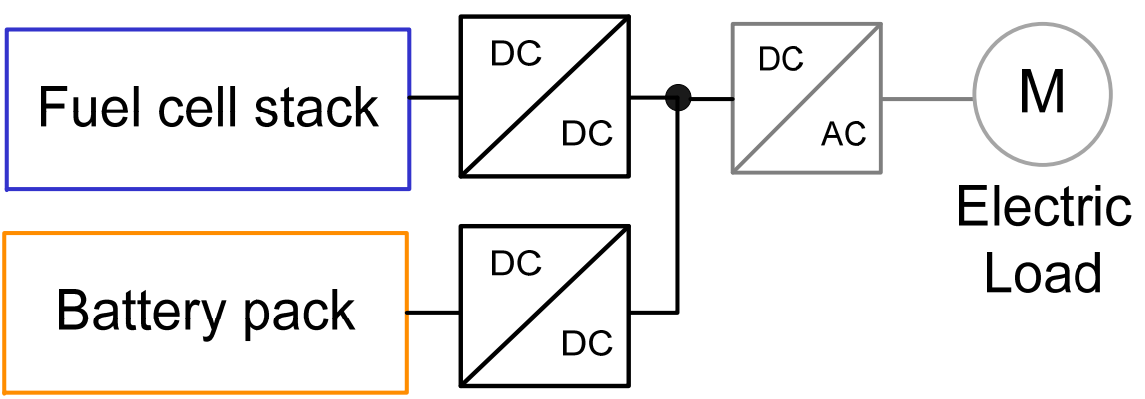

$\times$ DC/DC converter for potential separation

$\times$ DC/DC converter are expensive

$\times$ DC/DC converter require cooling system

Direct hybrid system

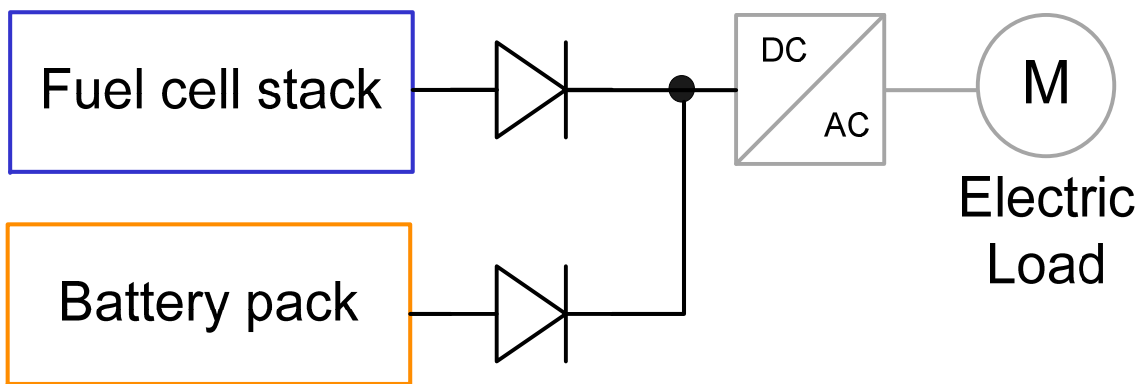

Advantages

$\checkmark$ No inductance

$\checkmark$ High efficiency

$\checkmark$ Lower cost

$\checkmark$ Light weight

$\checkmark$ Reliable

$\checkmark$ Passive elements

Disadvantages

High voltage spread 


\section{Concept of the direct hybrid}
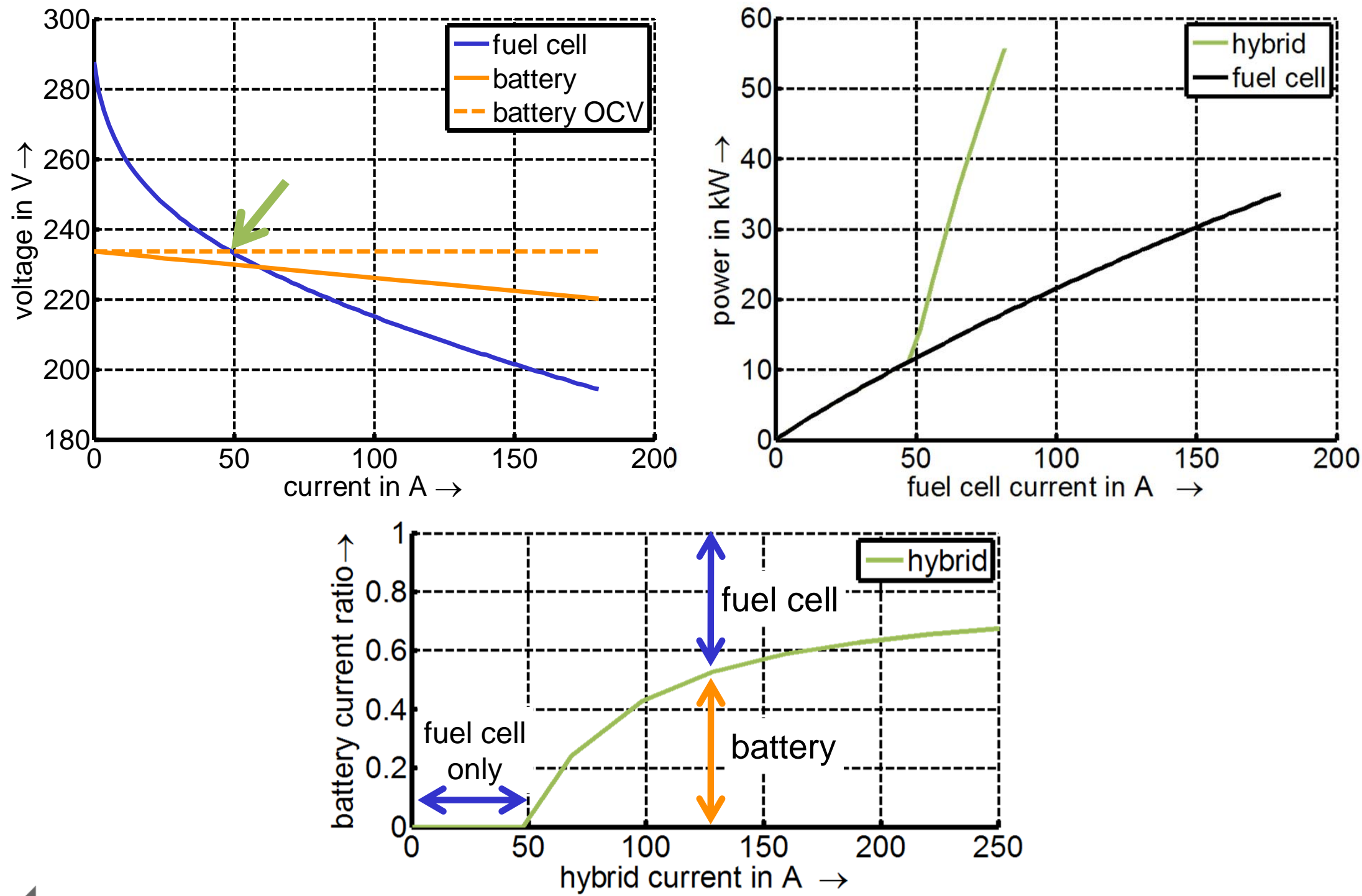


\section{Battery characteristics: State of charge (SOC)}
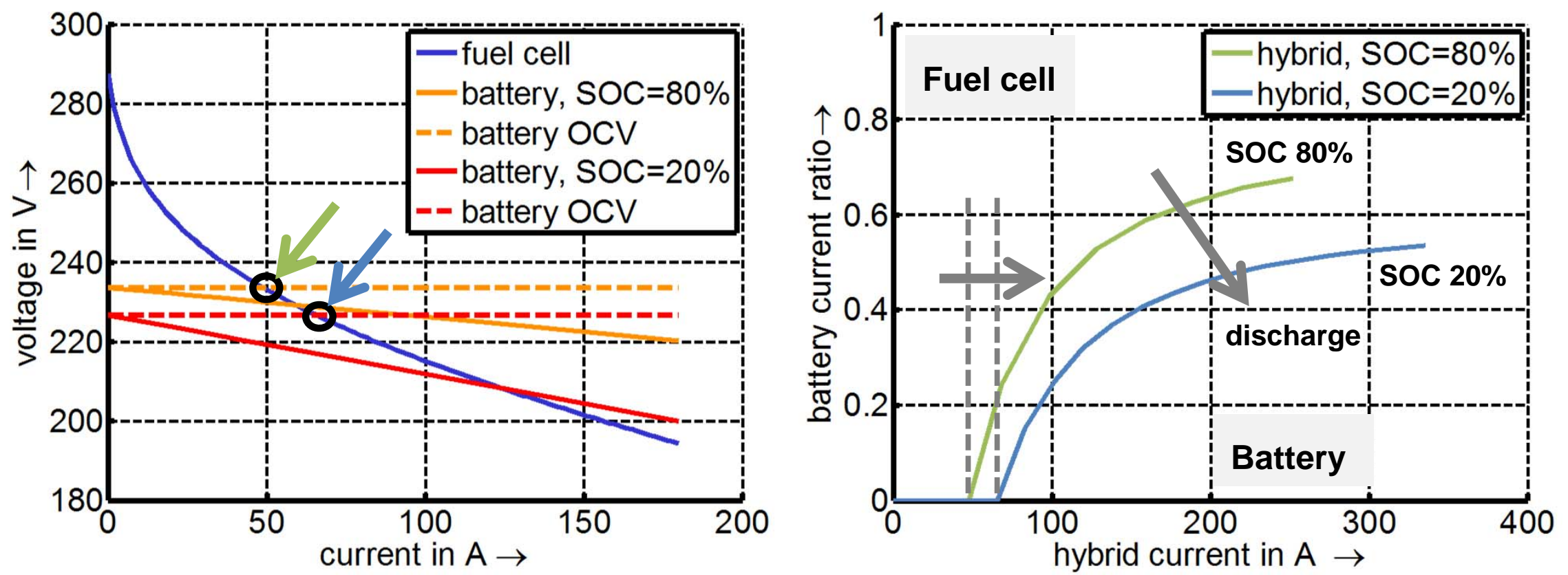

- Battery voltages depend on SOC and current

- I-U-characteristics change while battery is discharged

- Battery current ratio reduces at lower SOC
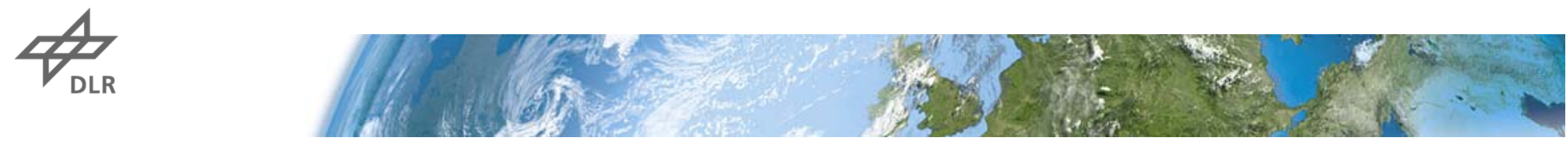


\section{Battery characteristics: Temperature}
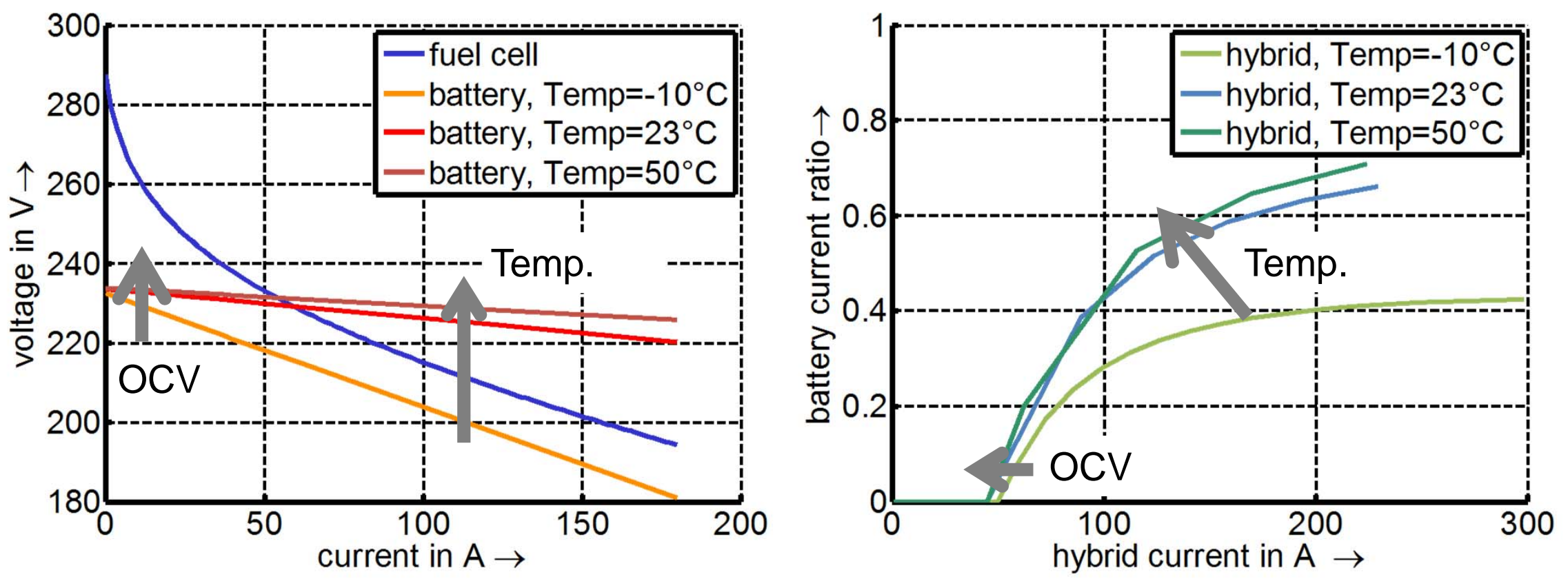

- Battery resistances decreases with higher temperature

- Battery current ratio decreases at lower temperature

- OCV slightly reduces at lower temperature

- Battery heats up over time due to ohmic losses
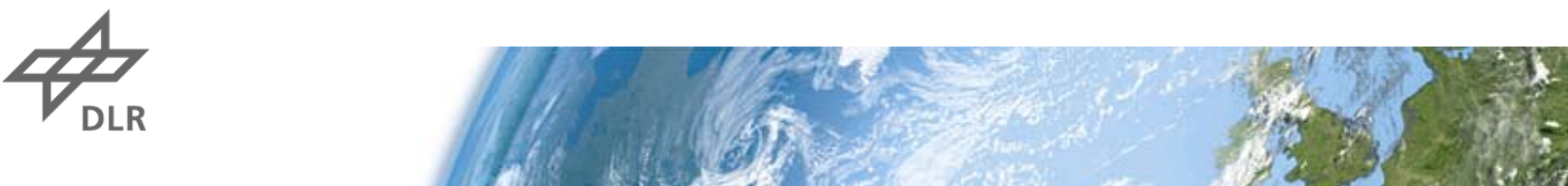


\section{Fuel cell degradation}
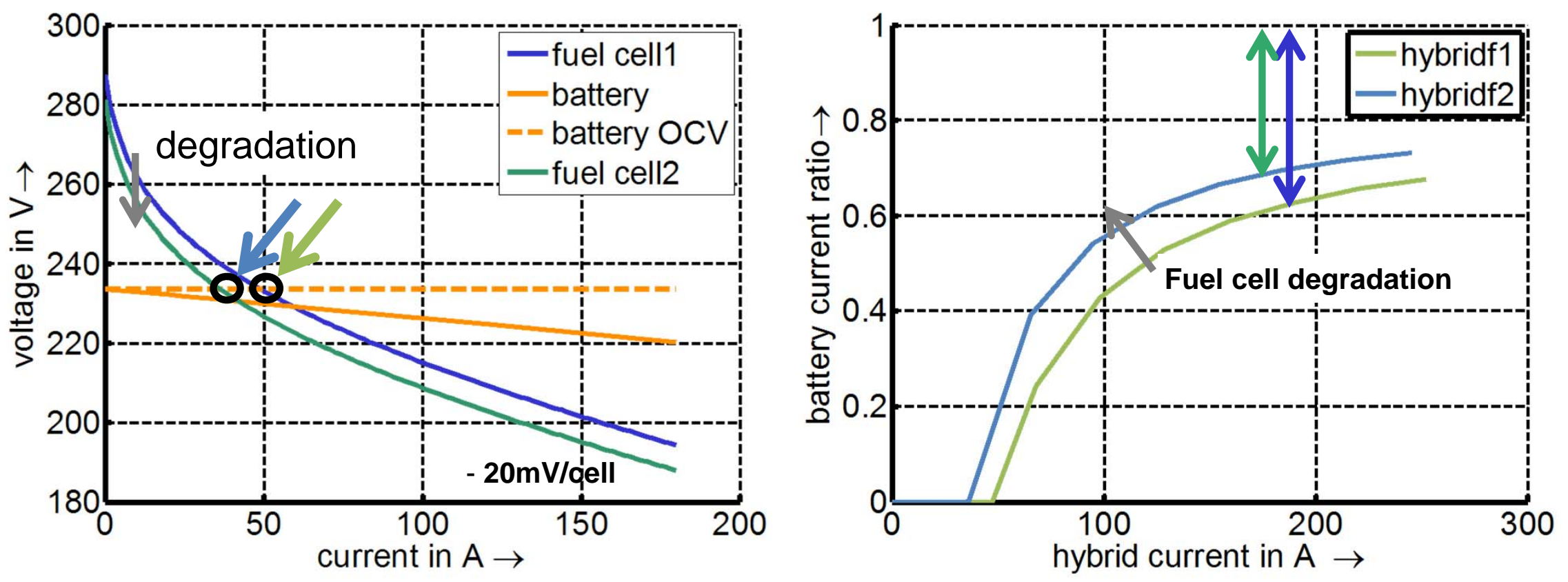

- Fuel cell degrades over time: voltages decreases

- Fuel cell current ratio is reduced over time
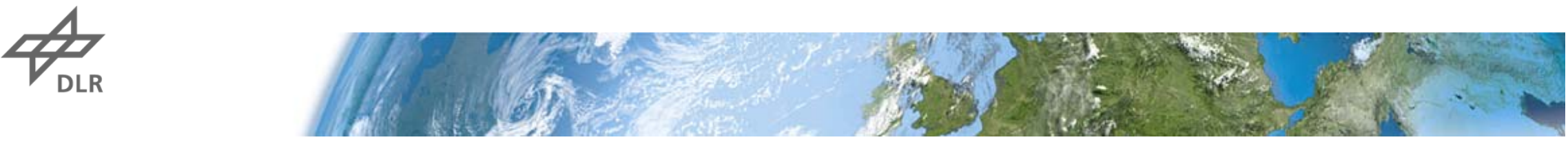


\section{Aircraft application: Battery Temperature}

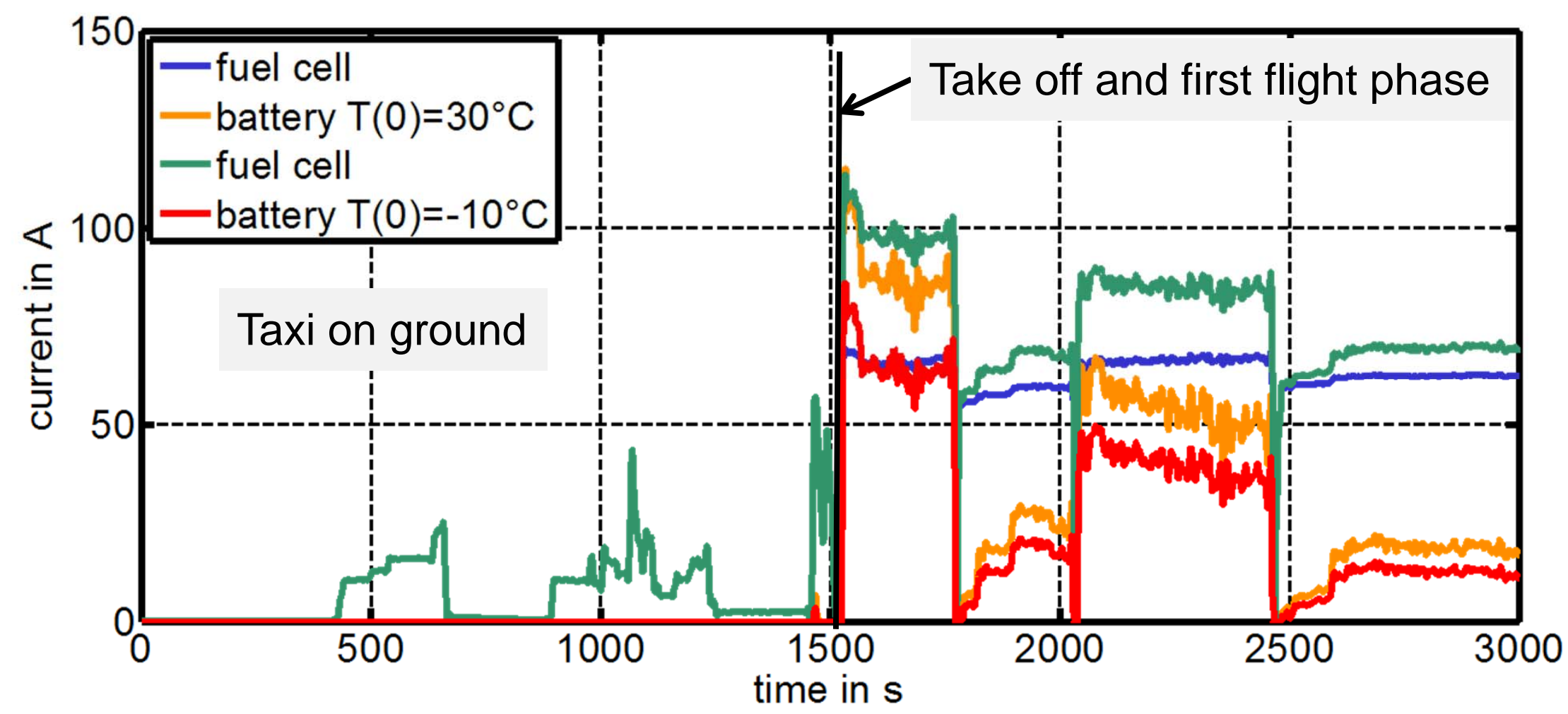

- Hybrid system/battery used only at high power requests

- Different initial battery temperatures

- Higher fuel cell current at lower temperature

- Battery heats up due to ohmic losses - less influence
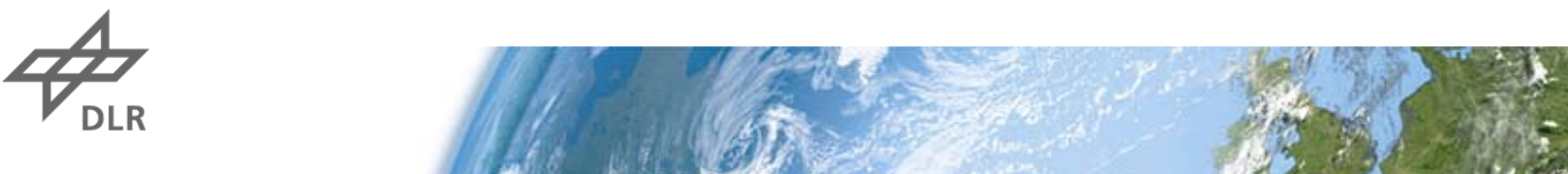


\section{Aircraft application: Fuel cell degradation}

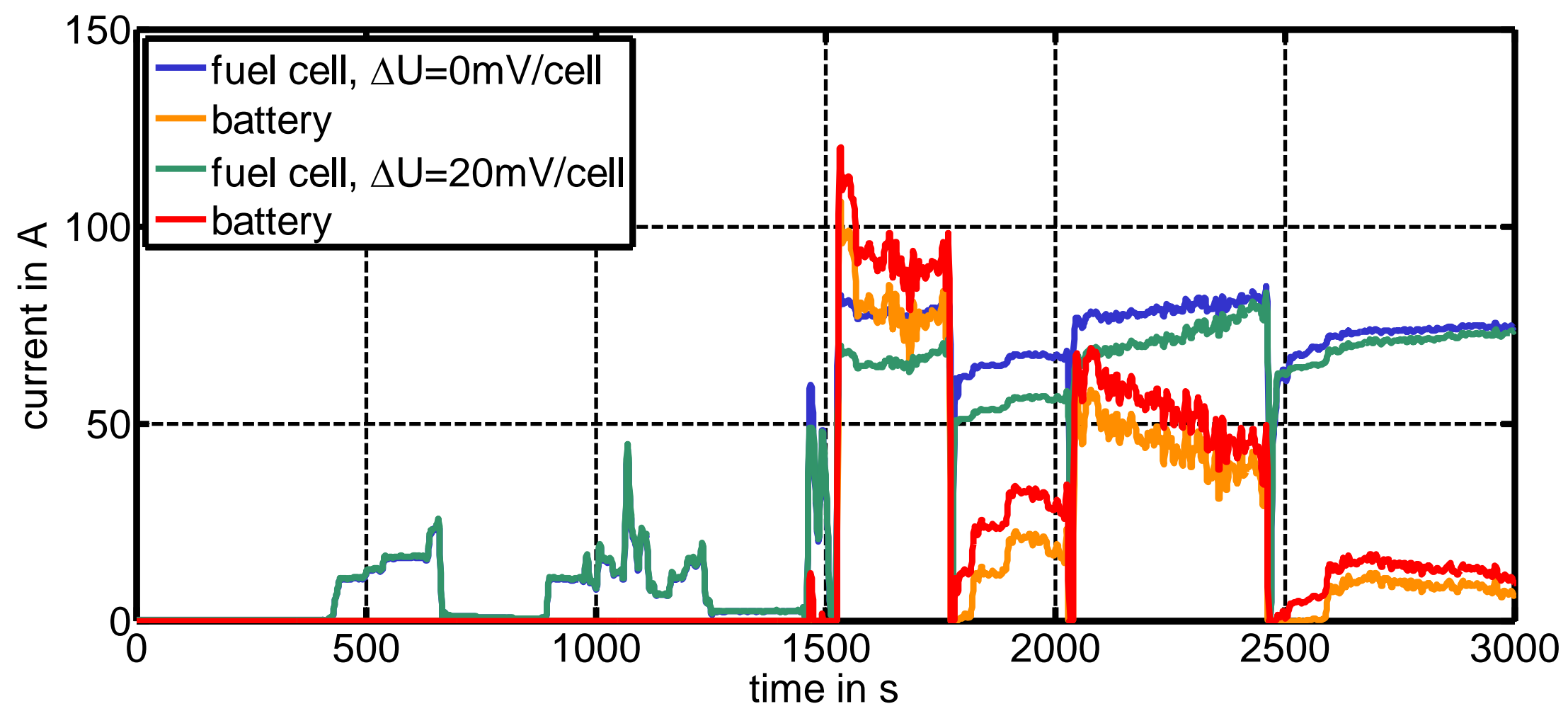

- Comparison between new and degraded fuel cell at room temperature

- Fuel cell current ratio decreases over time
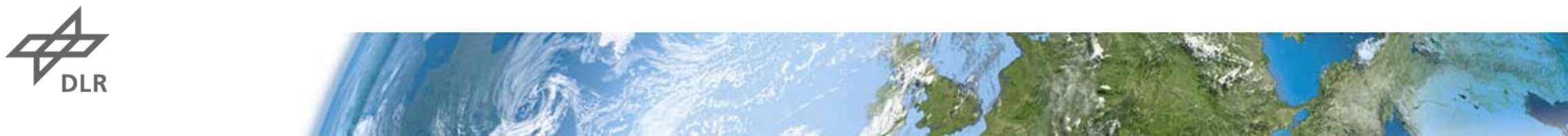


\section{Conclusions and Outlook}

- Hybrid characteristics influenced by

- Battery state of charge/temperature

- Fuel cell degradation

- Reliable design for aircraft application

- Low cost, high efficient, light weight

- Support fuel cell at high power request (e.g. flight start)

- Very promising results for aircraft application

- Next step: Integration and test with Antares DLR-H2 with improved FC Power

- Further work: Efficient dynamic applications

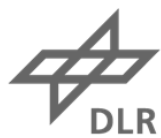


Thank you for your attention!

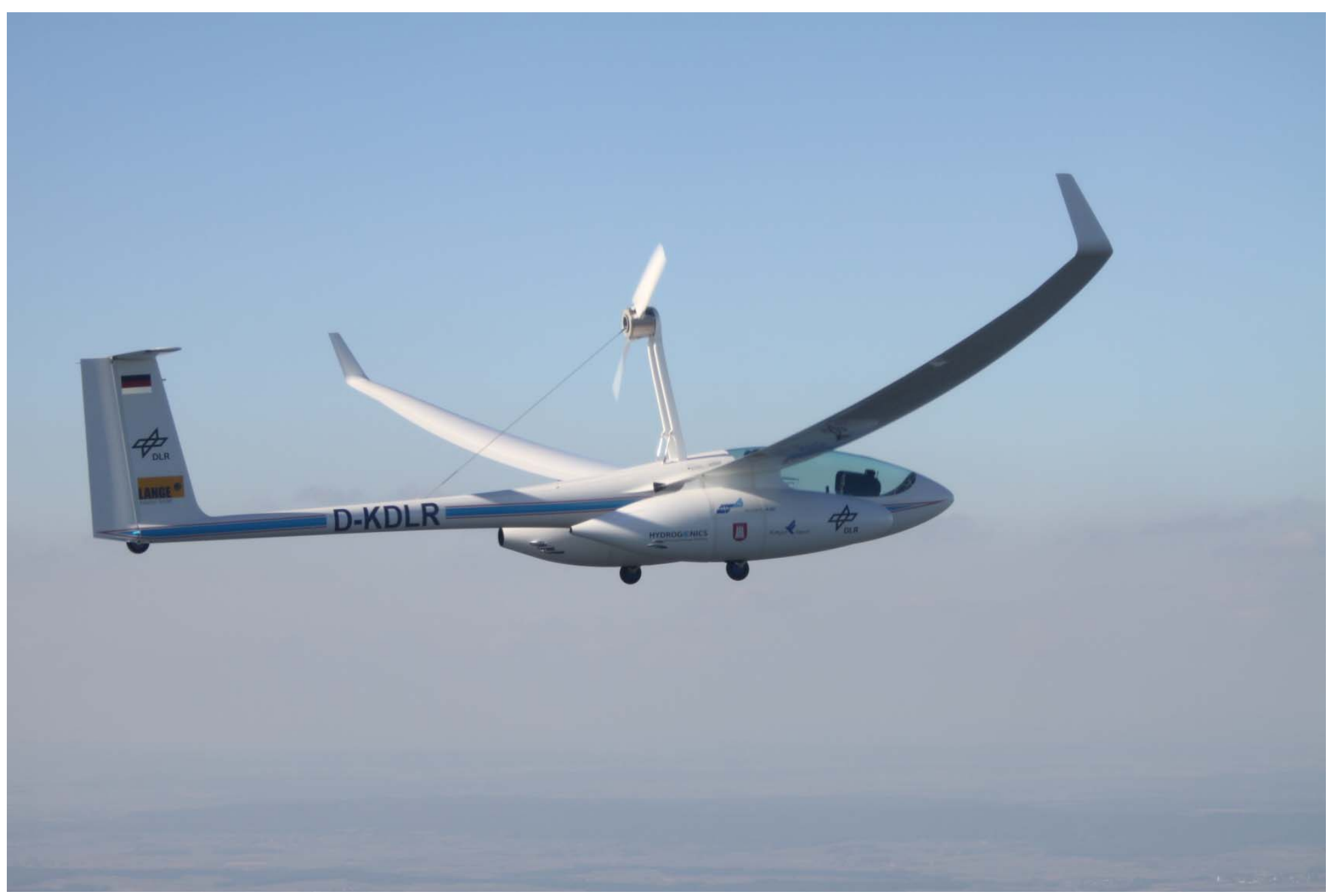

$f_{\mathrm{DLR}}$

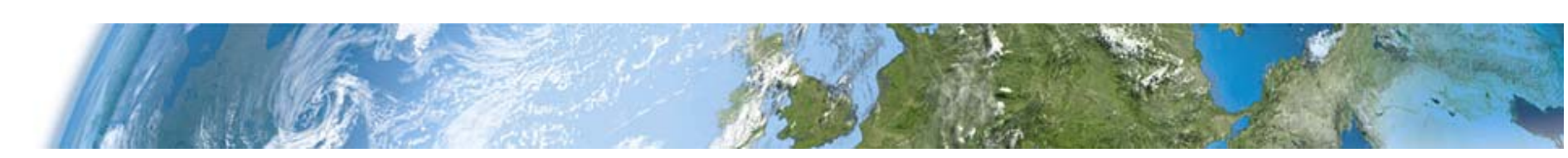

